\title{
Multi-objective optimization of ORC geothermal conversion system integrated with life cycle assessment
}

\author{
Dominika Matuszewska ${ }^{1, *}$, Marta $\mathrm{Kuta}^{1}$, and Jan Górski ${ }^{1}$ \\ ${ }^{1}$ AGH University of Science and Technology, Faculty of Energy and Fuels, Department of Thermal and Fluid Flow Machines, \\ al. A. Mickiewicza 30, 30-059 Krakow, Poland
}

\begin{abstract}
This paper details the development of a systematic methodology to integrated life cycle assessment (LCA) with thermo-economic models and to thereby identify the optimal exploitation schemes of geothermal resources. Overall geothermal systems consist of a superstructure of geothermal exploitable resources, a superstructure of conversion technology and multiple demand profiles for Swiss city. In this paper, an enhanced geothermal system has been chosen as exploitable resources. The energy conversion technology used in modelling is an organic Rankine cycle, which can be used to supply heat and electricity. In the Swiss case four demand profiles periods are considered: summer, interseason, winter and extreme winter, the city Nyon serving for the example case study. The multi-objective optimization system, that uses an evolutionary algorithm, is employed to determine the optimal scheme for some of the prepared models, with exergy efficiency and environmental impact as objectives.
\end{abstract}

\section{Introduction}

The use of geothermal resources for supplying simultaneously different energy services such as electricity, district heating and district cooling has recently gained interest. The optimal design of such systems requires knowledge of the geothermal resources that will be used, the selection of appropriate energy conversion technologies, and a specification of component operating conditions. This can be achieved by using process integration techniques and multiobjective optimization in a multi-period time perspective, with due regard to economic, thermodynamic and environmental criteria. While economic and thermodynamic analysis methods have been widely applied in this framework, the dynamic evaluation of environmental impact in a process design context is still relatively new. The environmental evaluation of geothermal systems should be performed from a life cycle perspective since the impact from drilling and construction is likely to be significant. Therefore, a life cycle assessment is the appropriate method to quantitatively evaluate and compare the different system configurations, including resources, conversion technologies and the services to be supplied. However, to serve as an effective design and evaluation tool, for the optimal configuration of geothermal systems, a life cycle inventory has to be fully integrated in the process design framework. It also has to be operated in a multi-period time perspective, to account for the variation in energy supply levels throughout the year.

\subsection{Literature review}

Energy conversion systems have been widely described in literature, starting from the description of individual technologies for the utilization of geothermal heat $[1,2]$, through working fluid selection in ORC systems [3], up to detail problems, which occur during exploitation $[4,5]$.

In case of life cycle assessment (LCA), Keoleian paper [6] in general has presented the use of LCA in product design context. Unfortunately, that work does not include the methodology to conduct LCA in a computer-aided optimization. The trade-offs between environmental and economic performance indicators in multi-objective optimization have been presented in work of Kniel, Delmarco, and Petrie [7], Azapagic and Clift [8], as well as Alexander, Barton, Petrie, and Romagnoli [9]. The biggest problem with these works is that they do not take under consideration multiperiod approach in the energy system design. Papandreou and Shang [10] present work about conducting LCA with multi-objective optimization in the field of energy system. The work is focused only on the energy based on fossil fuel sources and thus takes into account only gaseous emissions. The use of LCA in a multi-objective optimization with consideration of energy integration techniques is presented by Li, Maréchal, Bure, and Favrat [11], Bernier, Maréchal, and Samson [12].The work presents the relationship between the levelized cost of electricity and the life cycle global warming potential as performance indicators. The trade-off between the minimizing the environmental impact and increasing the

\footnotetext{
Corresponding author: dommat@agh.edu.pl
} 
efficiency has been described there as well as the usage of LCA in $\mathrm{CO}_{2}$ tax evaluation.

A systematic methodology for identification the optimal exploitation scheme of geothermal conversion systems has been presented in studies [13]. Thermoeconomic modeling was used to connect the exploitable geothermal resources with conversion technologies to provide multiple energy services. However, the LCA methodology was not considered in this evaluation. Report [14] provide the data for life cycle inventory for models of the geothermal exploitable resources and conversions technologies using Ecoinvent database. Although there were several studies on the LCA use in a process design context the first time the methodology for integration the LCA into thermo-economic models have been presented on the basis of biofuels [15].

\section{Research methodology}

Research methodology consisted of several steps. The first step included the integration of LCI data - specified in the Ruiz Dern study [14] - into the available geothermal resources, technologies and demand profile models. The integration was based on specific LCA methodology for process design integration, as has been presented below. The next step involved defining input data for various scenarios: geological data (geological profile with associated potential geothermal resources) for one or more given locations (for example in Switzerland), and yearly demand profiles for energy services. The next step involved defining the functional unit and systems limits for the life cycle assessment evaluation. The life cycle inventories have been integrated with realistic data to define a base case scenario. The base case scenario has been used to analyze the impact of the different life cycle stages and periods for the different geothermal system configurations, and identify the main impact contributions. In the next step a multi-objective optimization have been carried out to identify the tradeoffs and so arrived at the optimal configuration for the geothermal system. This would then be followed by an analysis of the influence of the life cycle assessment data on the general optimal configuration. Finally, the configuration has been compared to the base case scenario.

\subsection{Specific LCA methodology}

The thermo-economic design approach was based on a computational platform, which connected different models that were representative for the energy system design. To model interactions between each operational unit, involved the use of energy flow models of the process unit operations as well as integration techniques. The thermo-economic model for geothermal energy conversion systems, as well as the economic and environmental layers of the LCA model have also need to be added. The model with the LCA is presented in the figure below (fig. 1).

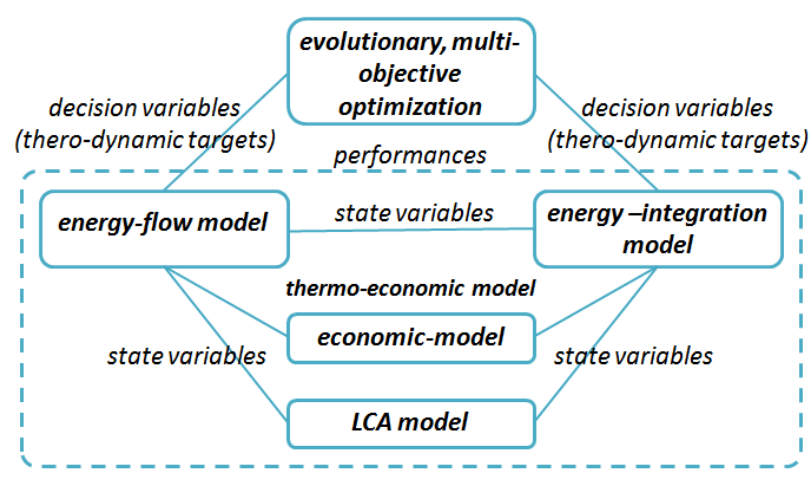

Fig. 1. Architecture of the process model [15].

The simulation results, such as mass and energy flows, were taken to create an energy integration model. The post-calculation phase was based on thermodynamic states and flow rates of the energy flow and energy integration models. A post-calculation phase has been used to size the equipment, estimate the cost and evaluate the performances of the process configuration. The Life Cycle Inventory (LCI) has been performed based on reference data in the EcoSpold format from the ecoinvent ${ }^{\circledR}$ life cycle inventories database and the simulation results $[16,17]$

Figure 2 presents previously developed methodology for the integration of LCA within a thermo-economic model.

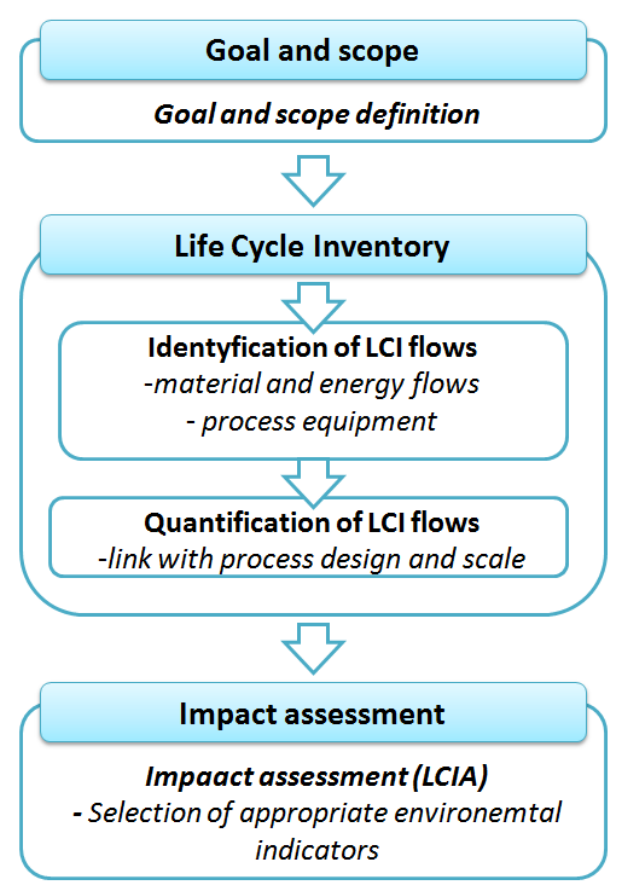

Fig. 2. Developed general methodology for LCA model conception [15].

Note that the LCA connection with the process design has been singled out in the figure. The crucial matter of listing LCI flows was to identify to which process units the flows were linked and their function. This identification was essential because flows were mathematically expressed as a function of the decision variable of thermo-economic model. The scaling of 
impacts due to changes in operating conditions and sizes of the process equipment also need to be considered. The mathematical expressions for LCI flows and impacts based on process equipment are included in the LCA, which makes it possible to calculate the whole LCI for a given process configuration. The Ecoinvent ${ }^{\circledR}$ life cycle inventories database has been used in the life cycle inventories process and impact assessment.

This paper put emphasis on preparing the proper methodology for integration the LCA with thermoeconomic model. However, from the LCA side the main goal of this work is to identify the most environmental friendly process configuration. The environmental impact is treated as one of the performance indicators, which is minimized during optimization.

The functional unit of the system is $1 \mathrm{kWh}$ available from the exploitable geothermal resources. The 'cradleto-grave' approach determined the boundaries of the system. During the evaluation, three phases (construction, operation and dismantling) of lifetime of geothermal power plant was considered.

Ecological Scarcity method has been used in evaluation, due to the fact of using 'distance to target' principle in evaluation of life cycle inventories. It used eco-factors, which are expressed as eco-point per unit of pollutant emissions or resources extraction. The ecofactors has been determined by both current emission situation and the political target of the Swiss environmental policy [18] In this method the varies tapes of eco-factor are aggregated $t$ a present pollution level, and compared with level defined by Swiss environmental policy. This is the main reason why the ecological scarcity method should be used only for Swiss context problem [19].

\section{Physical model development}

The possible combinations of three sub-systems that were modelled separately are considered. The overall geothermal conversion systems consist of the superstructure of potential exploitable geothermal resources, the superstructure of conversion technologies, the superstructure of conversion technologies and the multi-period demand profiles that define the demand for services.

The possible combination of the exploitable geothermal resources, conversion technologies, demand profiles and life cycle phases has been presented in fig. 3 .

\subsubsection{Geothermal resource model}

The superstructure of geothermal resources is divided into three types: Enhanced Geothermal System (EGS), deep aquifer and shallow aquifer. During the modelling of geothermal resources the emphasis was put on the information needed to evaluate these kinds of resources, such as geological data (thermal gradient, water mass flow rate, depth, etc.), geotechnical data (exploitation mode, drilling techniques, number of wells). Thermal gradient changes for each resource, were assumed to be linear. For residential areas of Nyon in Switzerland, it was set at $3.8^{\circ} \mathrm{C}$ for each $100 \mathrm{~m}$ of drilling depth.

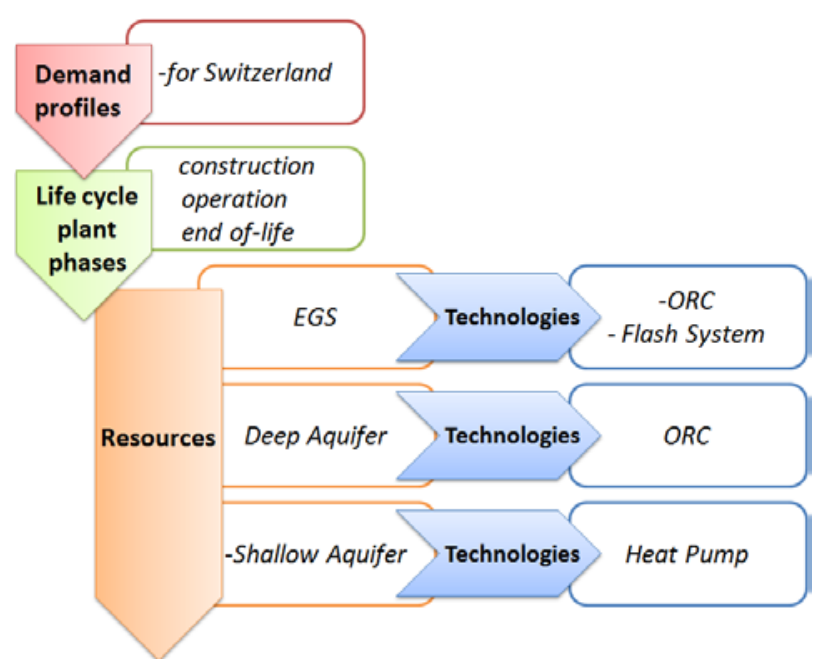

Fig. 3. The scheme of geothermal system combinations.

\subsubsection{Geothermal resource model}

The superstructure of geothermal resources is divided into three types: Enhanced Geothermal System (EGS), deep aquifer and shallow aquifer. During the modelling of geothermal resources the emphasis was put on the information needed to evaluate these kinds of resources, such as geological data (thermal gradient, water mass flow rate, depth, etc.), geotechnical data (exploitation mode, drilling techniques, number of wells). Thermal gradient changes for each resource, were assumed to be linear. For residential areas of Nyon in Switzerland, it was set at $3.8^{\circ} \mathrm{C}$ for each $100 \mathrm{~m}$ of drilling depth.

\subsubsection{Conversion technologies}

There are a number of ways of converting geothermal heat into useful energy. The flash systems, organic Rankine cycles and heat pumps are taken under consideration. The ways these technologies have been used depends mainly on geothermal conditions as well as the demand for heating and, or cooling in a particular region. A conversion technology superstructure is presented in fig. 4 below.

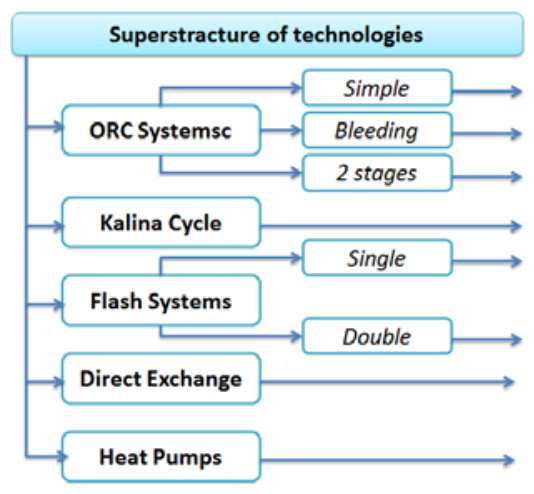

Fig. 4. Geothermal Conversion Technologies. 


\subsubsection{Energy services demand}

This study focuses on energy services demand under Swiss conditions (in the city of Nyon). In the Swiss case, four periods are covered. It is assumed that district cooling is not included in the evaluations. Electricity is also not included in the demands profiles - it is assumed that any electricity generated will be sold to the grid.

The Swiss demand profiles were based on data for the city of Nyon, Switzerland (Methodology for the Urban Energy Conversion Concept - An Example at Nyon, n.d.), and divided into four periods: summer, interseason, winter and extreme winter. The supply and return temperatures and load for each period are show in table 1 below.

Table. 1. The Swiss demand profiles.

\begin{tabular}{|c|c|c|c|c|}
\hline $\begin{array}{l}\text { Demand } \\
\text { profile }\end{array}$ & $\begin{array}{l}\text { Load } \\
{[\mathrm{kW}]}\end{array}$ & $\begin{array}{l}\text { Supply } \\
\text { temperature } \\
{\left[{ }^{\circ} \mathrm{C}\right]}\end{array}$ & $\begin{array}{l}\text { Return } \\
\text { temperature } \\
{\left[{ }^{\circ} \mathrm{C}\right]}\end{array}$ & $\begin{array}{l}\text { Operating } \\
\text { time }[\mathrm{h}]\end{array}$ \\
\hline \multirow[t]{2}{*}{ Summer } & 200 & 60 & 25 & \multirow[t]{2}{*}{525} \\
\hline & 300 & 25 & 21 & \\
\hline \multirow[t]{3}{*}{ Interseason } & 150 & 60 & 32 & \multirow{3}{*}{3942} \\
\hline & 500 & 32 & 26 & \\
\hline & 300 & 28 & 20 & \\
\hline \multirow[t]{5}{*}{ Winter } & 100 & 60 & 50 & \multirow{5}{*}{4205} \\
\hline & 1200 & 50 & 40 & \\
\hline & 100 & 40 & 34 & \\
\hline & 700 & 34 & 28 & \\
\hline & 100 & 28 & 10 & \\
\hline \multirow{5}{*}{$\begin{array}{l}\text { Extreme } \\
\text { winter }\end{array}$} & 100 & 75 & 65 & \multirow{5}{*}{88} \\
\hline & 1750 & 65 & 50 & \\
\hline & 150 & 50 & 40 & \\
\hline & 1000 & 40 & 32 & \\
\hline & 100 & 32 & 10 & \\
\hline
\end{tabular}

\section{System resolution}

The one-run system resolutions for default values for each modelled system were launched to check for any technical problems with the models and model conversation. Further, this paper will focus only on date from the multi-objective optimization which was run for enhanced geothermal system with organic Rankine cycle for seven different fluids: benzene (BZ), toluene, isobutane (IC4), n-butane (N4), cycle-butane (CYC4), isopentane (IC5), n-pentane (N5). The environmental impact was calculated from single points chosen from sets of optimized system solutions.

\subsection{Objective function}

The models can be optimized by taking into account thermodynamic, economic and environmental performance indicators. In this study, only thermodynamic and environmental criteria are considered. The exergy efficiency and environmental impact are selected as objective functions.

The exergy efficiency was chosen because it considers the environment during evaluation. Exergy efficiency is defined as the ratio of the output exergy to the input exergy:

$$
\eta=\frac{\sum_{p=1}^{n_{p}} \dot{E}_{p}^{-} t_{p}+\sum_{p=1}^{n_{p}} \dot{E} x_{p}^{-} t_{p}}{\sum_{p=1}^{n_{p}} \dot{E} x^{+} t_{p}}
$$

where: $\dot{E}^{-}$- the electricity produced by the overall system during period $\mathrm{p}, \mathrm{t}_{\mathrm{p}}-$ the duration of the period $\mathrm{p}$, $\dot{E} x^{+}-$the exergy transfer to the district heating during period $\mathrm{p}$.

The specific impact of district heating per $\mathrm{kWh}$ generated was chosen as the environmental indicators. It is calculated as the total life cycle impact for the overall system divided by the amount of district heating supplied during the lifetime of the system [20]:

$$
I_{Q}=\frac{\sum_{p=1}^{n_{p}} \sum_{i=1}^{n_{e O}} I_{O_{i, p}}+\sum_{i=1}^{n_{e c}} \max \left(I_{C_{i}}\right)_{p}+\sum_{i=1}^{n_{e e}} \max \left(I_{E_{i}}\right)_{p}}{\sum_{p=1}^{n_{p}} \dot{Q}_{p}^{-} t_{p} t_{l i f e}}
$$

where: $I_{O}$ - is the impact due to the operation phase for period $\mathrm{p}$ of the LCI element $\mathrm{i}, \mathrm{n}_{\mathrm{eo}}$ - the total number of LCI elements from the operation phases, $I_{C}-$ is the impact of the construction phase of the element I for period $p, n_{e c}$-is the total number of LCI elements from the construction phases, $\mathrm{I}_{\mathrm{E}}$ - is the impact due to the endof-life phase of the element I for period $p, n_{e e}-$ is the total number of LCI elements from the end-of-life phases and $t_{\text {life }}-$ is the overall lifetime of the geothermal system (in this study it was assumed to be 40 years).

\section{Validation and optimization}

The validated models were optimized using a genetic algorithm. The multi-objective optimizations were run to show the trade-off between the thermodynamic and environmental criteria. The decision variables chosen for organic Rankine cycles were the evaporation temperature in the $80-120^{\circ} \mathrm{C}$ range, the superheating temperature in the $120-230^{\circ} \mathrm{C}$ range, the depth in the $3000-6000 \mathrm{~m}$ range and the reinjection temperature in the $70-110^{\circ} \mathrm{C}$ range. The multi-objective optimization of enhanced geothermal system with organic Rankine simple cycle has been launched for seven different working fluids and evaluated with use of Ecological Scarcity impact assessment method.

To determine the optimal configuration of geothermal conversion system, two objective function were considered: exergy efficiency and impact on environment. The optimal solution for analyzed working fluids has been presented as Pareto curve in fig. 5 .

The optimization gave two sets of solution for substance like iso-butane, n-butane and cyclo-butane. The first set has been composed by solution with low exergy efficiency, while the second one by the higher one. It can be seen, that the solution with lower exergy efficiency 
have lower impact on environmental than those with higher exergy efficiency. However, both sets have harmful influence on environment (all obtained results for those substances are above $\mathrm{x}$-axis). The impact on environment has been less harmful in case of low exergy efficiency set of solutions, due to the fact that in those case there is no need for deep drilling (blue points in figure 5). The increase of drilling depth results in growth

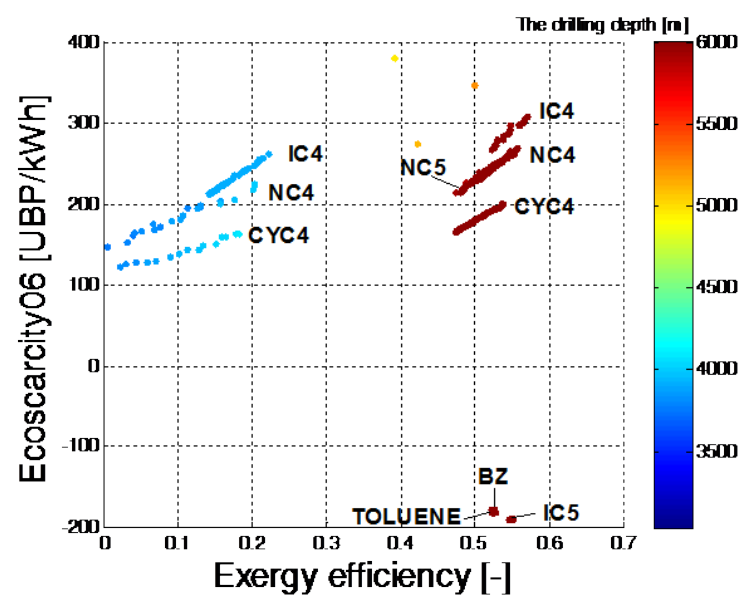

Fig. 5. Pareto curve foe Ecoscarcity 06 and exergy efficiency with varying the drilling depth for EGS ORC simple system with different working fluids. of emissions and extraction (among others from steel for casing, diesel, starch, bentonite used for drilling mud, etc.). In addition, the drilling depth has got an effect on costs of investment - they grow as the depth of a drilling well increases. Considering that the drilling costs in this type of facilities are one of the most significant, further work should take this into account.

The sets of solution depend strongly not only on drilling depth but also with another decision variable which strongly correlates with depth - a superheating temperature. Deeper drilling is aimed at obtaining higher temperature of geothermal brine at the outlet from a production well, and thus later - superheating temperature (and ultimately exergy efficiency). The growth of superheating temperature in ORC system is correlated with growth of exergy efficiency. However, low heat exchange coefficient for used working fluids can lead to expensive and large heat exchanger, which should be included in future development. Only three working fluids from seven analyzed showed beneficial impact on environment and they are: benzene, toluene and iso-pentane. In addition, these working fluid obtained exergy efficiency from top of range and can be recommended in analyzed case.

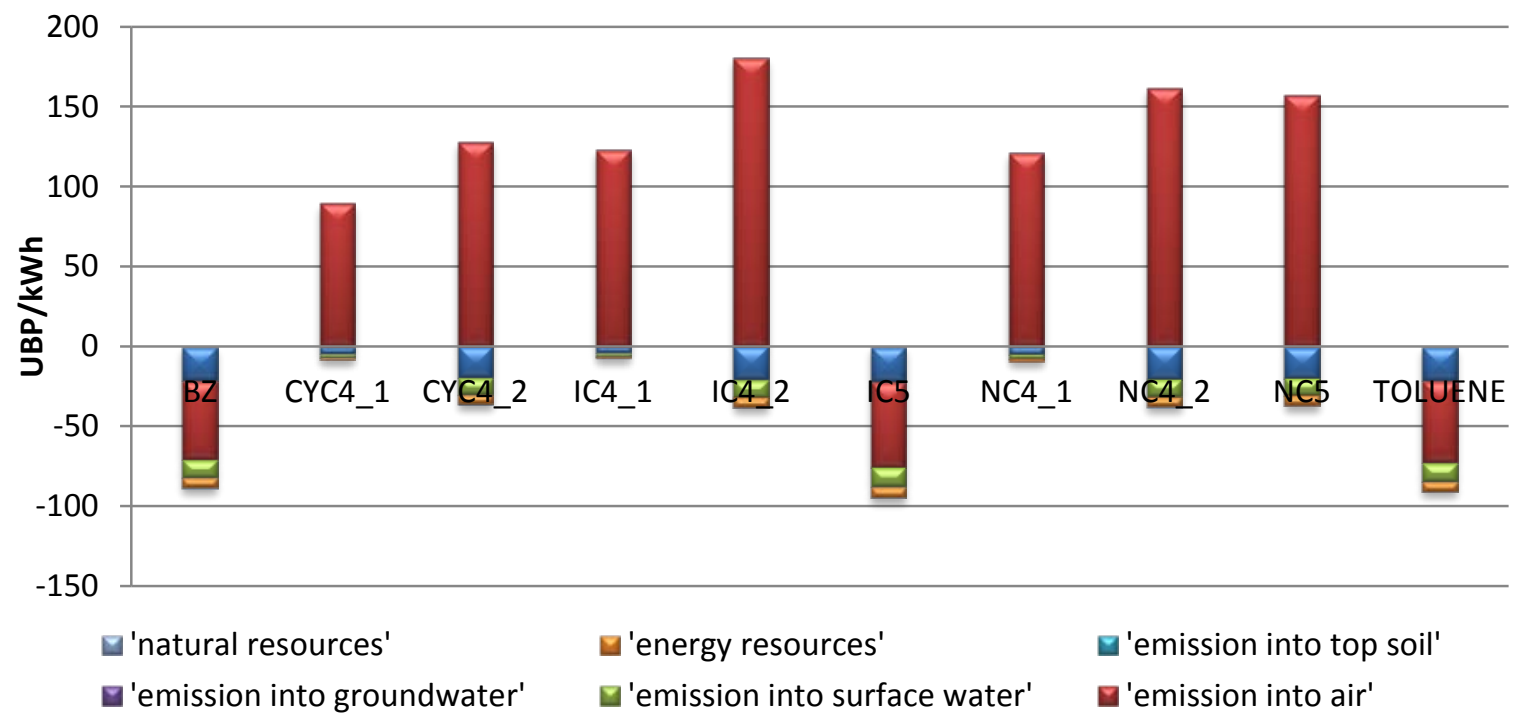

Fig. 6. Environmental impact based on Ecoscarcity06 calculated by LCIA categories.

The multi-objective optimization gave a set of points with optimal system configurations for different working fluids. The single points for each LCIA method have been selected from this set. The parameters of these points were chosen as constant to launch one-run system resolutions. In based of that the analysis of particular systems configuration on environment were provided. The results are presented to show that the given problem can be presented in many ways. The one-rum system resolutions for selected optimal results has been presented in fig. 6 .
From optimal results for ecological scarcity method, different set of points was chosen to show the impact of each category. The method shows that the most significant contribution into impact have emissions into air, deposited waste and emissions into surface water. It is connected with the substance used for reservoir enhancement as well as working fluid losses. For butane substances, performances for two points were chosen to one-run system resolution what is presented in fig. 6 . The low efficiency point is marked with index 1 , while the high efficiency - with index 2. 


\section{Conclusion}

In this work, the methodology for integration the life cycle assessment (LCA) in thermo-economic models has been presented. The identification of the optimal exploitation scheme geothermal resources is presented. The emphasis of the work is put on environmental criteria. The overall geothermal conversion system was modeled as three separate sub-systems: the exploitable geothermal resources, conversion technologies and demand profiles of useful services. The methodology of integration LCA into thermo-economic model was applied to the real case for Swiss city Nyon. For this purpose, the superstructure of organic Rankine cycle and enhanced geothermal system was used. The main aim of optimization was determination the most suitable working fluid in the light of objective functions. Seven different working fluids were considered: benzene, cyclo-butane, iso-butane, iso-pentane, n-butane, npentane and toluene.

The environmental impact of the system was evaluated based on LCA Ecological Scarcity methodology. The influence on results had a couple of factors e.g. approach used in each method, the way of normalized and weighting the impact categories, the choice of categories, etc.

The results obtained by ecological scarcity have harmful influence on environment. Iso-butane, n-butane and cyclbutane belongs to this group of working fluid, which negatively effect on environment. The beneficial impacts have toluene, benzene and iso-pentane. The ecological scarcity method was designed in based on Swiss environmental policy. In fact this method, is the most suitable one to analysis the problems in Swiss context. Analyzing the obtained results the quantification of the effect on environment of a particular technology can be evaluated using different LCA methods. To create the process model, it is possible to use process integration techniques (e.g. pinch point analysis, costing or lifecycle analysis). This action helps to define the optimal configuration of the system. The choice of optimal performances depends on decision-maker and a given problem. The optimization returns a set of optimal solutions, which can be used optionally.

This work focuses on optimization with thermodynamic and environmental performances indicators. However, it is important to remember that nowadays costs are crucial matter in making decision, so the optimization with economic performance indicator should be done. It would be desirable to show if there is any trade-off between beneficial and environmental friendly projects. This work was supported by AGH - University of Science and Technology (Project 11.11.210.376).

\section{References}

1. R. DiPippo, Geothermal Power Plants, $4^{\text {th }}$ Edition (Butterworth-Heinemann, 2015)

2. W. Nowak, A. Borsukiewicz-Gozdur, Transactions of the Institute of Fluid-Flow Machinery 114, 57-65 (2003)
3. D. Mikielewicz, J. Mikielewicz, Applied Thermal Engineering 30(16), 2357-2362 (2010)

4. M. Lukawski, J. W. Tester, R. DiPippo, Sustainable Energy \& Fuels 5 (2017)

5. D. Matuszewska, K. Sztekler, J. Gorski, MATEC Web of Conferences 18, 03005 (2014)

6. G. Keoleian, Journal of Cleaner Production 1, 143149 (2003)

7. G. Kniel, K. Delmarco, J. Petrie, Environmental Progress 15, 221-228 (1996)

8. A. Azapagic, R. Clift, Computer \& Chemical Engineering 23, 1509-1526 (1999)

9. B. Alexander, G. Barton, J. Petrie, J. Romagnoli, Computer \& Chemical Engineering 24, 1195 - 1200 (2000)

10. V. Papandreou, Z. Shang, Computer \& Chemical Engineering 32, 1589-1602 (2008)

11. H. Li, F. Maréchal, M. Burer, D. Favrat, D, Energy 31, 3117-3134 (2006)

12. G. Bernier, F. Maréchal., R. Samson, Energy 35, 1121-1128 (2010)

13. M. Hoban, L. Gerber, F. Maréchal, Integrate Thermo-economic Modeling of Geothermal Resources for Optimal Exploitation Scheme Identification. http:/www.ecos2010.ch (2010)

14. A. M. Ruiz Dern, Life Cycle Assessment of Geothermal Energy Conversion Systems. (Master's thesis. Industrial Energy System Laboratory of the Swiss Technology Institute of Lausanne. Lausanne, Switzerland, 2010)

15. L. Gerber, M. Gassner, F. Maréchal, Integration of LCA in a thermo-economic model for multiobjective process optimization of SNG production from woody biomass. $19^{\text {th }}$ European Symposium on Computer Aided Process Engineering - ESCAPE19 (2009)

16. R. Frischknecht, N. Jungbluth, Overview and Methodology, ecoinvent report No 1. Tech. rep. ecoinvent center (2007)

17. R. Frischknecht, N. Jungbluth, H-J. Althaus, G. Doka, R. Dones, T. Heck, S. Hellweg, R. Hischier, T. Nemecek, G. Rebitzer, M. Spielmann, International Journal of Life Cycle Assessment 10, 3-9 (2005)

18. R. Frischknecht, R. Steiner, N. Jungbluth, The Ecological Scarcity Method - Eco-Factors 2006, (Federal Office for the Environment FOEN. Switzerland, 2009)

19. R. Bolliger, EnergyTechnologies Dacumentation Version 2.1 Revision 2113 (Industrial Energy Systems Laboratory, Ecole Polytechnique Fédérale de Lausanne. Switzerland, 2010)

20. G. Leda, F. Maréchal, Applied Thermal Engineering 43, 29-41 (2012) 